\title{
Forty-year study of rates of homicide by people with schizophrenia and other homicides in the Chuvash Republic of the Russian Federation
}

\author{
Andrei Golenkov, Matthew Large, Olav Nielssen and Alla Tsymbalova
}

\section{Background}

The extent to which rates of homicide by people with or without schizophrenia vary over time has theoretical and practical implications in understanding homicide by people with mental illness.

\begin{abstract}
Aims
The aim was to report on the rates of homicide by people diagnosed with schizophrenia over time in a region in which there were dramatic changes in the overall rates of homicide.
\end{abstract}

\section{Methods}

An examination of homicide by people diagnosed with schizophrenia in the course of judicial psychiatric examination, and the rate of other homicide in the Chuvash Republic of the Russian Federation between 1981 and 2020 was undertaken.

\section{Results}

During the 40 years of the study a total of 5741 people faced legal proceedings for a homicide offence, of whom 179 (3.1\%) were diagnosed with schizophrenia. During the study period the average annual total homicide rate rose from about 9 per 100000 in the 1980s, peaked at 17 per 100000 in the 1990s before falling to 13 per 100000 in the 2000s and 6 per 100000 in the 2010s.
Rates of homicide by people with schizophrenia also rose and fell over this period and were significantly associated with the rates of other homicide ( $r=0.503$, d.f. $=38, P=0.001)$.

\section{Conclusions}

The rise and fall in rates of homicide by people diagnosed with schizophrenia in parallel to total homicide suggests that homicidal behaviour might not be intrinsic to the clinical manifestations of the illness, and might instead reflect a heightened vulnerability to social factors that are associated with homicide by people without schizophrenia.

\section{Keywords}

Homicide; schizophrenia; alcohol; criminal responsibility; Russia (Chuvashia).

\section{Copyright and usage}

(C) The Author(s), 2021. Published by Cambridge University Press on behalf of the Royal College of Psychiatrists. This is an Open Access article, distributed under the terms of the creative Commons Attribution licence (https://creativecommons.org/ licenses/by/4.0/), which permits unrestricted re-use, distribution, and reproduction in any medium, provided the original work is properly cited.

\section{Background}

There is a well-recognised but poorly understood association between schizophrenia and homicide offending. Meta-analyses of available studies show a fourfold increased risk of homicide offending among men with schizophrenia and an eightfold increased risk among women compared with rates of homicide offending by people without schizophrenia, ${ }^{1}$ and that a pooled estimate of $6.5 \%$ of homicide offenders have schizophrenia. ${ }^{2}$ The traditional view has been that the elevated homicide risk among people with schizophrenia is because homicide risk is intrinsic to clinical manifestations of schizophrenia, particularly persecutory delusional beliefs. ${ }^{3}$ This view has contributed to an emphasis on the treatment of psychotic symptoms and on measures to contain people with schizophrenia who are perceived as potentially violent. ${ }^{3}$ This view was supported by studies suggesting that homicide rates by people with severe mental illness would be more or less fixed over time and between regions, in line with the stability in prevalence of severe mental illness. ${ }^{4,5}$ However, a 2009 meta-analysis of 18 available population-based studies found that rates of homicide by people with schizophrenia are heterogeneous and are strongly correlated to rates of other homicide. This study contradicts earlier views about the stability and causes of rates of homicide by people with schizophrenia and suggests that other explanations, including the possibility that rather than being intrinsic to the psychopathology of schizophrenia, people with schizophrenia might be more vulnerable to the same risk factors that determine homicide rates in the general community. ${ }^{2}$ The implications of this finding include that homicide by people with schizophrenia might best be prevented by limiting the exposure to factors known to be associated with violence in the community, such as access to firearms and limiting alcohol and other drug use, as much as by treatment and hospital admission. One limitation to the 2009 meta-analysis $^{2}$ was that it examined aggregated homicide rates over the duration of the included studies and did not examine changes in rates or in the relationships between the rates of homicide by people with and without schizophrenia over time.

Several studies have examined the trends in homicide committed by a broader class of people considered to have a mental disorder. In England and Wales, rates of homicide by people with mental illness (defined as the total of those judged to have diminished responsibility, infanticide, or as being unfit to stand trial or not guilty due to mental illness) rose steeply with rates of other homicide after World War Two, before falling just as steeply, while the rate of other homicides continued to rise. ${ }^{6}$ Another pattern was observed in New Zealand between 1970 and 2000 where the total homicide rate rose annually between 1970 and 1990 before falling in the last decade of the study, whereas the proportion of homicide by people defined as 'mentally abnormal' (not guilty due to mental illness, infanticide and those unfit to stand trial) fell throughout the study, initially because homicide by people who were not mentally ill was rising and later because mental illness verdicts were falling faster than other court outcomes. $^{7}$

In Denmark, homicide by people with psychosis (defined using ICD-8 criteria) were reported to be stable during a period of rising homicide rates between 1956 and 1970, but then increased in parallel with total homicide rates between 1970 and the mid-1980s. ${ }^{8}$ In Iceland homicide by people with mental illness (defined as 
schizophrenia, manic depression and morbid jealousy) rose more quickly than rapidly rising rates of other intentional homicides in the period 1970 to $1984 .^{9}$ More recently, a study from Ontario, Canada found a non-significant fall in homicide offending by people who were mentally ill during a period when the rate of other homicide fell more. ${ }^{10}$ To date the only study that focused on changes in rates of homicide by people with schizophrenia found a rise in the absolute number of homicide offenders with schizophrenia during a period in which other homicide rates fell in England and Wales. ${ }^{11}$ The major limitation in interpreting this group of studies as an indicator of the association between homicide offending by people who are mentally ill compared with those who are not mentally ill is the differences between studies in the way mental illness is diagnosed and defined in law between jurisdictions and over time. ${ }^{2,12}$

\section{Aims}

We have previously reported on the characteristics of offenders with schizophrenia and other mental disorders from The Chuvash Republic of the Russian Federation, a region with both a high total homicide rate and a high rate of homicide by people with schizophrenia. ${ }^{13-15}$ Previously we found that almost half of all homicide offenders had at least one mental disorder, including alcohol dependence experienced by $16 \%$ of offenders and schizophrenia experienced by over $4 \%$ of offenders. ${ }^{15}$ In this paper we report on the trends in rates of homicide by people with schizophrenia and without schizophrenia (other homicides) during a period of 40 years when the rate of total homicide rose and fell dramatically. We hypothesised that if rates of homicide by people with schizophrenia were fixed over time that they would not be correlated with the rates of homicide by people without schizophrenia and that the proportion of homicides by people with schizophrenia would fall while other homicide rates were rising and would rise when other homicide rates were falling. In other words, the rate of homicide by people with schizophrenia did not change when the overall rate of homicide changed .

\section{Method}

\section{Sample}

The study examined a data-set of all homicides in Chuvash Republic of the Russian Federation between January 1981 and December 2020. The Chuvash Republic has a population of over 1.2 million living in an area of around $18000 \mathrm{~km}^{2}$, centred in the city of Cheboksary on the Volga River about $650 \mathrm{~km}$ east of Moscow. A third of the population live in Cheboksary and $40 \%$ are considered to be rural. During the period of the study, and as in the rest of Russia, people in the Chuvash Republic who are charged with a homicide offence are referred for psychiatric evaluation under Section 21 of the Russian Penal Code. ${ }^{13-16}$ Referral for judicial psychiatric examination by a panel of three psychiatrists is at the discretion of the investigators and the court. Some accused are not referred because there are no doubts about their sanity, and some individuals who are accused refused to be examined. However, most accused are examined, and the sample includes the majority of offenders referred for a formal evaluation, including all offenders suspected of having a psychiatric disorder. Data was also available about homicides that were immediately followed by the suicide of offenders known to mental health services.

\section{Case identification and data extraction}

Demographic, clinical and criminological data were extracted from the case files, which included the judicial psychiatric report, hospital records, out-patient notes and legal documents. About one-third of the offenders had been personally examined by either A.G. or A.T. The demographic data extracted were age, gender, occupation, marital status and years of education and the clinical data included psychiatric diagnosis, age at onset, previous treatment, pattern of symptoms, history of brain injury, and substance misuse, and the criminological data included previous convictions, method of homicide and judicial outcome. The psychiatric diagnoses were made using the version of the ICD that was current at the time of the judicial examinations. For the purpose of this study the psychiatric diagnoses in each individual was made by retrospective chart review using ICD-10 criteria. ${ }^{17}$

\section{Statistical analysis}

Non-age-adjusted homicide rates were calculated using the number of annual homicide incidents and the annual population of Chuvashia, as measured by the census or imputed using linear assumptions in the intervening years. The association between rates of homicide by people with schizophrenia and other homicide and the association between the rates of other homicide and the proportion of all homicides committed by people with schizophrenia were examined with a Pearson correlation coefficient using untransformed homicide rates.

The changes in homicide rates by people with and without schizophrenia and changes in the proportion of homicides (homicides by people with schizophrenia/total homicides) committed by people with schizophrenia over time were examined using Kendall's Tau rank correlation coefficient over the whole period of the study and over two equal periods (1981-2000 and 20012020) in which the homicide rates were, respectively, rising and falling. In order to illustrate the association between homicide in schizophrenia and other homicide, rates were displayed as $\log _{10}$ $(1+$ homicide rate per million population per annum) so as to avoid the scale minimisation effects that can arise because of the low base rate of homicide offending by people with mental illness. ${ }^{18}$ Possible differences in the characteristics of male and female homicide offenders with schizophrenia were examined using $t$-test and chi-square $\left(\chi^{2}\right)$. When one or several cells contained five individuals or less, a Fisher's Exact test was used. All tests were performed in a two-tailed form. The data were analysed using SPSS Version 27 (SPSS Inc. Chicago, IL, USA).

\section{Ethical approval}

Approval for the research was obtained from the Ethics Committee of the Medical Faculty of Chuvash State University, and the Chuvash Association of Psychiatrists, Narcologists, Psychotherapists and Medical Psychologists (a branch of the Russian Society of Psychiatrists). As the study only uses statistical information, no oral or written consent was taken from the individuals of the study.

\section{Results}

\section{Rates of homicide}

In the 40 years from the beginning of 1981 and the end of 2020, 5741 people faced legal proceedings for a homicide offence, and 3410 homicide offenders were referred for psychiatric evaluation. Over this period there were more homicide victims than offenders because the police did not solve every case, some offenders had multiple victims, and some offenders died by suicide or died prior to being examined. A small number of offenders from other parts of Russia were examined elsewhere. The homicide clearance rates, defined as an offender being identified by the 
Table 1 Homicide by people with schizophrenia in Chuvashia 1981-2020

\begin{tabular}{|c|c|c|c|c|c|c|c|}
\hline & $\begin{array}{l}\text { Homicide offenders } \\
\text { with schizophrenia, } \\
n\end{array}$ & $\begin{array}{l}\text { Female homicide } \\
\text { offenders with } \\
\text { schizophrenia, } n\end{array}$ & $\begin{array}{l}\text { Adolescents, } \\
n \text { (age, years) }\end{array}$ & $\begin{array}{c}\text { Recidivist } \\
\text { homicide } \\
\text { offence, } n \text { (year } \\
\text { index) }\end{array}$ & $\begin{array}{l}\text { Two victims } \\
\text { or more, } n \text { ( } n \\
\text { of victims) }\end{array}$ & $\begin{array}{l}\text { Total people with } \\
\text { schizophrenia in } \\
\text { Chuvashia, } n\end{array}$ & $\begin{array}{l}\text { Total homicide } \\
\text { in Chuvashia, } n\end{array}$ \\
\hline 1981 & 2 & & & 1 (1966) & & & 113 \\
\hline 1982 & 5 & & & & 1 (4) & & 107 \\
\hline 1983 & 3 & & $1(19)$ & & & 3102 & 121 \\
\hline 1984 & 3 & 1 & & 1 (1965) & & & 146 \\
\hline 1985 & 1 & & & & & & 106 \\
\hline 1986 & 5 & & & & & 3182 & 84 \\
\hline 1987 & 4 & & & & 1 (3) & & 94 \\
\hline 1988 & 7 & 1 & $1(12)$ & & 1 (2), 1 (2) & & 118 \\
\hline 1989 & 2 & & & & & & 132 \\
\hline 1990 & 6 & 3 & & 1 (1978) & & & 149 \\
\hline 1991 & 1 & & & & & & 127 \\
\hline 1992 & 5 & & & 1 (1983) & & & 194 \\
\hline 1993 & 7 & 2 & & $1(1976)$ & & 4583 & 220 \\
\hline 1994 & 7 & 1 & $1(17)$ & & 1 (2) & & 238 \\
\hline 1995 & 4 & & 1 (19) & & & & 246 \\
\hline 1996 & 4 & 1 & & & 1 (2) & & 210 \\
\hline 1997 & 6 & & & & 1 (2) & 4491 & 233 \\
\hline 1998 & 6 & & & 1 (1988) & & & 223 \\
\hline 1999 & 5 & 1 & & 1 (1994) & & & 257 \\
\hline 2000 & 10 & 2 & & & & & 250 \\
\hline 2001 & 2 & & & & & & 229 \\
\hline 2002 & 5 & 1 & $1(18)$ & & & & 203 \\
\hline 2003 & 10 & & 1 (19), 1 (15) & 1 (1988) & $1(2)$ & & 202 \\
\hline 2004 & 5 & & $1(17)$ & & 1 (2) & 4875 & 186 \\
\hline 2005 & 6 & & & 1 (1990) & & & 175 \\
\hline 2006 & 8 & & & 1 (1999) & $1(4), 1$ (2) & & 153 \\
\hline 2007 & 8 & & $1(19)$ & 2 (1994), (1995) & & & 128 \\
\hline 2008 & 5 & & $1(19)$ & $\begin{array}{c}3(1992,1998 \\
2000)\end{array}$ & & & 129 \\
\hline 2009 & 4 & & & & & & 106 \\
\hline 2010 & 7 & 1 & & $2(1987,1997)$ & 1 (2) & 4812 & 102 \\
\hline 2011 & $3^{\mathrm{a}}$ & 1 & & & $1(2)$ & & 99 \\
\hline 2012 & 2 & 1 & & & 1 (2) & & 82 \\
\hline 2013 & 4 & & & 1 (2003) & & & 94 \\
\hline 2014 & 1 & & & & & & 93 \\
\hline 2015 & $7^{\mathrm{a}}$ & 3 & $1(15)$ & & 1 (3) & & 101 \\
\hline 2016 & 3 & & & & & & 73 \\
\hline 2017 & 2 & & & & & & 86 \\
\hline 2018 & 0 & & & & & 4747 & 42 \\
\hline 2019 & 2 & & & & & 4659 & 46 \\
\hline 2020 & 2 & & & & & 4736 & 44 \\
\hline Total & 179 & 19 & 11 & $18^{\mathrm{b}}$ & $15(36)^{c}$ & & \\
\hline
\end{tabular}

police, were more than $90 \%$ in the period of the study. Of those subjected to judicial examination, $46.7 \%$ were found to have at least one mental disorder, and $7.7 \%$ were found to be not responsible for their actions because of mental disorder according to the Russian Criminal Code. ${ }^{18}$

During the study period 179 homicide offenders were identified as having schizophrenia, including 14 recidivist offenders who committed both homicides between 1981 and 2020 (Table 1). The population of Chuvashia rose slightly from 1.304 million in 1981 to 1.347 million in 1993 , and subsequently fell by about $10 \%$ to 1.224 million in 2020 .

During the four decades of the study the rates of homicide by people without schizophrenia rose and fell:

(a) 1981-1990: average 8.9 per 100000 person-years;

(b) 1991-2000: average 16.4 per 100000 person-years:

(c) 2001-2010: average 12.5 per 100000 person-years;

2011-2020: average 6.1 per 100000 person-years.
Rates of homicide by people with schizophrenia also rose and fell in the same periods:

(a) 1981-1990: average 0.28 per 100000 person-years;

(b) 1991-2000: average 0.41 per 100000 person-years;

(c) 2001-2010: average 0.47 per 100000 person-years;

(d) 2011-2020: average 0.21 per 100000 person-years.

The annual rate of homicide by people with schizophrenia was strongly correlated with the rate of other homicide (Pearson's $r=$ $0.503, r^{2}=0.253, F=12.9$, d.f. $=38, P=0.001$ ) (Fig. 1). There was no significant association between the rates of other homicide and the proportion of all homicides committed by people with schizophrenia (Pearson's $r=-0.21, r^{2}=0.045, P=0.19$ ).

In the period 1981-2000 rates of homicide by people with schizophrenia rose significantly $(\operatorname{tau}(\tau)=0.33 P=0.04)$ as did those without schizophrenia $(\tau=.67 P=<0.0001)$. In the period 2001-2020 rates of homicide by people with schizophrenia fell 


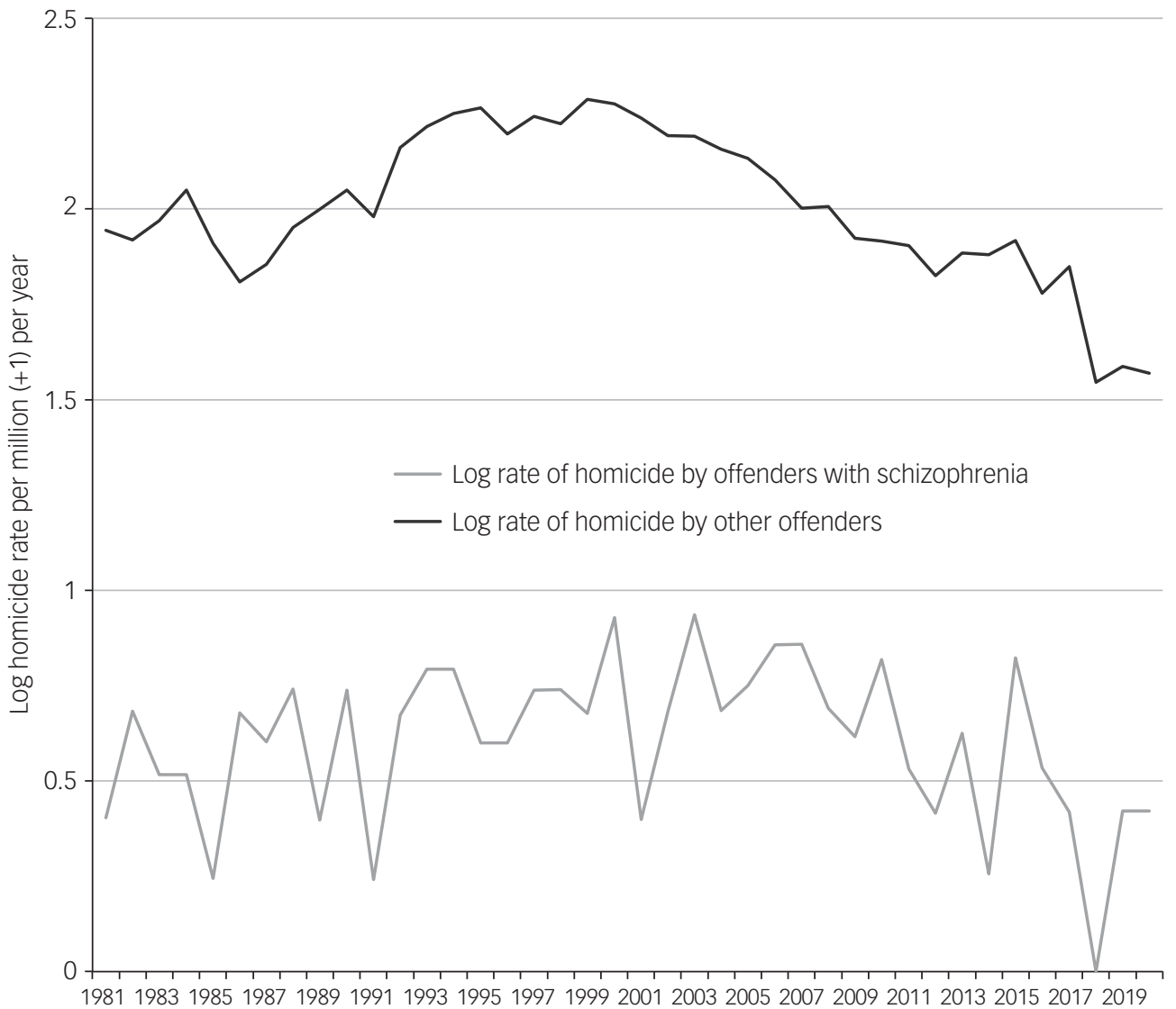

Fig. 1 Homicide rates by people with schizophrenia and other homicide in Chuvashia 1981 to 2020.

significantly $(\tau=-0.35 P=0.03)$ as did those by people without schizophrenia $(\tau=-0.86 P<0.0001)$ (Fig. 1).

The proportion of homicides by people with schizophrenia did not change over the 40 years of the study $(\tau=0.15, P=0.18)$, during the period 1981-2000 when rates of homicide were rising $(\tau=-0.05$ $P=0.75)$ or in the period 2001-2020 when rates of homicide were falling $(\tau=0.06 P=0.7)$

\section{Characteristics of homicides by people with schizophrenia}

In total 160 homicide incidents were committed by men with schizophrenia and 19 (10.7\%) by women with schizophrenia. Adolescents (defined as individuals aged between 12 and 19 years) with schizophrenia committed 11 (6.2\%) homicide offences (Table 1). There were 18 recidivist homicides by people with schizophrenia, 17 of which took place in rural areas, including 14 who committed their first and second homicide in the period of the study and 4 whose initial homicide was before 1981. There were 15 homicides with multiple victims, including 3 by women, and 2 homicides followed by suicide by people who were known to have schizophrenia. Thirty-one offenders were sentenced to indefinite hospital care, and the remainder received fixed terms (Table 2).

\section{Discussion}

\section{Main findings}

This study examines the rates of homicide by people with schizophrenia over a period of 40 years in a region that had a dramatic rise and equally dramatic decline in the rate of homicide. The results confirm the well-recognised over-representation of people with schizophrenia among homicide offenders, but also suggest that the rate of homicide by those with schizophrenia is correlated with changes in the rate of other homicide and that the proportion of homicides committed by people with schizophrenia might not fall when other homicide rates are higher and might not rise as other homicides become less common.

\section{Interpretation of our findings}

Although the reasons for the five- to tenfold increase in homicide risk associated with schizophrenia remains uncertain, the findings of this study suggest that the increased rate is at least partly because of a greater exposure or greater sensitivity of people with schizophrenia to more general risk factors for homicide, including factors such as substance use and social disadvantage, rather than an intrinsic or inevitable propensity to lethal violence associated with the illness.

In this study the $r^{2}$ statistic indicated that about one-quarter of the variance in the rate of homicide associated with schizophrenia was explained by the changes in the overall rate of homicide. This can be compared with the results of a 2009 meta-analysis that found that three-quarters of the variance in rates of homicide in schizophrenia between jurisdictions was explained by the rates of other homicide. ${ }^{2}$ Hence both cross-sectional and longitudinal studies suggest that homicide rates by people with schizophrenia are not fixed over time and between regions and that social factors that influence homicide by people without schizophrenia, for example, alcohol and other drug use, levels of violence in the community, and the efficiency of the police in preventing crimes influence the likelihood of a person with schizophrenia committing a homicide offence. However, the moderate $R^{2}$ value in the association between rates of homicide in people with schizophrenia and 


\begin{tabular}{|c|c|c|c|c|c|c|c|c|c|c|c|}
\hline \multirow[b]{2}{*}{ Age, years: mean (s.d.), range } & \multicolumn{2}{|c|}{$\begin{array}{c}\text { Total } \\
\text { offenders }\end{array}$} & \multicolumn{2}{|c|}{ Female offenders } & \multicolumn{2}{|c|}{ Male offenders } & \multirow[t]{2}{*}{$\chi^{2}$ (d.f.) } & \multirow[t]{2}{*}{$P$} & \multirow[t]{2}{*}{$\begin{array}{c}\text { Total, } \\
n\end{array}$} & \multirow[t]{2}{*}{$\begin{array}{c}\text { Female, } \\
n\end{array}$} & \multirow[t]{2}{*}{ Male, $n$} \\
\hline & 36.84 & (12.43) & 37.73 & (12.33), 24-70 & 36.84 & (12.64) $12-63$ & & & & & \\
\hline $\begin{array}{l}\text { Comorbid traumatic brain injury, } \\
n(\%)\end{array}$ & 41 & $(24.85)$ & 1 & $(5.26)$ & 40 & (27.39) & 5.675 & 0.018 & 165 & 19 & 146 \\
\hline Marital status, $n(\%)$ & & & & & & & $9.737(3)$ & 0.020 & & & \\
\hline Single & 99 & $(60.00)$ & 9 & $(47.37)$ & 90 & $(61.64)$ & & & 165 & 19 & 146 \\
\hline Divorced & 24 & (14.55) & 2 & (10.53) & 22 & (15.07) & & & 165 & 19 & 146 \\
\hline Widow & 1 & $(0.60)$ & 1 & $(5.26)$ & - & - & & & 165 & 19 & - \\
\hline Married (civil marriage) & 41 & (24.85) & 7 & (36.85) & 34 & (23.29) & & & 165 & 19 & 146 \\
\hline Location, rural, $n$ (\%) & 93 & (56.36) & 10 & (52.6) & 83 & $(56.85)$ & 0.353 & & 165 & 19 & 146 \\
\hline Education, $n(\%)$ & & & & & & & 8.496 (4) & 0.075 & & & \\
\hline No formal education & 2 & $(1.21)$ & 1 & $(5.26)$ & 1 & $(0.68)$ & & & 165 & 19 & 146 \\
\hline Attended school & 56 & (33.94) & 2 & (10.53) & 54 & $(37.00)$ & & & 165 & 19 & 146 \\
\hline Completed school & 78 & $(47.27)$ & 13 & (68.42) & 65 & $(44.52)$ & & & 165 & 19 & 146 \\
\hline College education & 21 & (12.73) & 2 & (10.53) & 19 & (13.01) & & & 165 & 19 & 146 \\
\hline University education & 8 & $(4.85)$ & 1 & $(5.26)$ & 7 & $(4.79)$ & & & 165 & 19 & 146 \\
\hline $\begin{array}{l}\text { Age at onset of schizophrenia, } \\
\text { mean (s.d.) }\end{array}$ & 22.1 & $(7.5)$ & 24.57 & $(9.61), 15-55$ & 22.52 & $7.30(8-47)$ & & & & & \\
\hline $\begin{array}{l}\text { Duration of schizophrenia, mean } \\
\text { (s.d.) }\end{array}$ & 14.7 & $(10.8)$ & 13.00 & $(11.25), 0.5-36$ & 14.28 & $(10.71), 0.5-36$ & & & & & \\
\hline \multicolumn{12}{|l|}{ Legal outcomes, $n(\%)$} \\
\hline Conviction & 46 & (27.88) & 1 & (5.26) & 45 & (30.82) & 6.807 & 0.009 & 165 & 19 & 146 \\
\hline $\begin{array}{l}\text { Treatment in a psychiatric } \\
\text { hospital by court order }\end{array}$ & 31 & (18.79) & - & - & 31 & $(21.23)$ & 6.456 & 0.010 & 165 & - & 146 \\
\hline Suicidal behaviour & 34 & (20.61) & 8 & (42.11) & 26 & (17.81) & 6.067 & 0.013 & 165 & 19 & 146 \\
\hline Previous criminal conviction & 46 & $(27.88)$ & 4 & $(21.10)$ & 42 & (28.77) & 0.955 & & 165 & 19 & 146 \\
\hline Method of homicide, $n(\%)$ & & & & & & & $12.713(6)$ & 0.047 & & & \\
\hline Beaten & 39 & $(21.79)$ & 7 & (36.85) & 32 & $(20.00)$ & & & 179 & 19 & 160 \\
\hline Stab-cut & 93 & (51.96) & 9 & (47.37) & 84 & $(52.50)$ & & & 179 & 19 & 160 \\
\hline Strangled & 25 & (13.97) & 1 & $(5.26)$ & 24 & (15.00) & & & 179 & 19 & 160 \\
\hline Firearm & 2 & $(1.12)$ & - & - & 2 & $(1.25)$ & & & 179 & - & 160 \\
\hline Set fire & 1 & $(0.55)$ & - & - & 1 & $(0.63)$ & & & 179 & - & 160 \\
\hline Threw from a height & 1 & $(0.55)$ & 1 & $(5.26)$ & - & - & & & 179 & 19 & - \\
\hline Several ways & 18 & $(10.06)$ & 1 & $(5.26)$ & 17 & $(10.62)$ & & & 179 & 19 & 160 \\
\hline $\begin{array}{l}\text { Victims and circumstances } \\
\qquad(n=200), n(\%)\end{array}$ & & & & & & & $35.990(4)$ & $<0.001$ & & & \\
\hline Children $^{a}$ & 17 & (8.50) & 9 & (39.13) & 8 & (4.52) & & & - & 23 & 177 \\
\hline Spouses (couple) & 19 & (9.50) & 2 & $(8.70)$ & 17 & $(9.60)$ & & & - & 23 & 177 \\
\hline Relatives & 78 & $(39.00)$ & 10 & $(43.47)$ & 68 & (38.42) & & & - & 23 & 177 \\
\hline Acquaintances (neighbours) ${ }^{b}$ & 79 & (39.50) & 2 & $(8.70)$ & 77 & $(43.50)$ & & & - & 23 & 177 \\
\hline Strangers & 7 & (3.50) & - & - & 7 & (3.96) & & & - & - & 177 \\
\hline Two victims or more, $n(\%)$ & 15 & (8.38) & 3 & (15.79) & 12 & (7.50) & 0.632 & & 179 & 19 & 160 \\
\hline Alcohol intoxication, $n$ (\%) & 83 & $(46.37)$ & 1 & $(5.26)$ & 82 & $(51.25)$ & 16.351 & $<0.001$ & 179 & 19 & 160 \\
\hline On the street, $n(\%)$ & 35 & (19.55) & 2 & (10.53) & 33 & (20.63) & 1.836 & & 179 & 19 & 160 \\
\hline Attempts to conceal, $n$ (\%) & 21 & (11.73) & 1 & $(5.26)$ & 20 & (12.50) & 1.699 & & 179 & 19 & 160 \\
\hline
\end{tabular}

other homicide does suggest that there are other factors that influence the rate homicide in schizophrenia that operate independently to those associated with total homicide. These might include the availability and quality of psychiatric care, variation in the prevalence of schizophrenia, and the specific impact of substance use on people with schizophrenia.

The decline in the total rate of homicide in Chuvashia in the past 20 years is striking, and may be because of greater economic prosperity and the re-establishment of social order after the turbulent glasnost years. The decline may also be related to the ageing of the population, as many people of working age have moved elsewhere, and a rise in the proportion of women in the population. There was an increase in the number of people known to have schizophrenia in Chuvashia during the years of the study that might be as a result of an increase in the identification and reporting of patients with schizophrenia by a larger mental health workforce. Hence, it is also possible that an increase in availability of treatment contributed to the decline in homicide offences by people with schizophrenia, as suggested by the near elimination of recidivist homicide offences by people with schizophrenia in the past decade and the over-representation of recidivists in rural areas where services are less available. During the period of the study there were no changes to the laws governing psychiatric treatment, which has been proposed as a possible reason for changes in rates of homicide by people who are mentally ill in the USA, along with the quality of services. ${ }^{19}$

A decline in the consumption of alcohol in Chuvashia might also have been important. During the period of the study alcohol consumption in Chuvashia fell from being above the Russian national average to well below the national average ${ }^{20}$ during a period in which the national per capita alcohol consumption fell by more than $40 \%{ }^{21}$ About half of the offenders with schizophrenia $(83 / 179,46 \%)$ were reported to be intoxicated with alcohol at the time of the offence, a pattern that had not changed in the decade since an earlier report. ${ }^{14}$

\section{Strengths and limitations}

Strengths of this study are the complete nature of the sample and related statistical information, consistency in the way the psychiatric 
examinations were recorded and an absence of changes to relevant sections of the legal code. Limitations of the study include that some homicide offenders did not receive a judicial examination, not all homicides were solved by the police, and the absence of information about the mental state of some of the homicide offenders who died by suicide before they could be examined.

\section{Implications}

A more reliable estimate of the extent to which rates of homicide by people with schizophrenia vary from other homicide rates might be obtained by meta-analysis once further longitudinal studies have been conducted in other jurisdictions. The extent of this correlation has implications for our understanding of the reasons for homicide by people with schizophrenia, and the degree to which systems of treatment for psychosis, and more general measures to reduce violence and homicide in the community might play a role in the prevention of homicide by people with emerging and established mental illness.

Andrei Golenkov (D, MD, PhD, DSc, Chuvash State University, Cheboksary, Russia Matthew Large (iD), BSC (Med), MBBS, FRANZCP, Prince of Wales Hospital and University of New South Wales, Australia; Olav Nielssen (1D, MBBS, MCrim, PhD, FRANZCP, Faculty of Medicine and Health Sciences, Macquarie University, Australia; Alla Tsymbalova,

MD, Department of Judicial-Psychiatric Examination, Republic Psychiatric Hospital Cheboksary, Russia

Correspondence: Andrei Golenkov. Email: golenkovav@inbox.ru

First received 15 May 2021, final revision 2 Oct 2021, accepted 4 Oct 2021

\section{Data availability}

The complete data-set is held by A.G. and is available for research purposes on reasonable request and ethical review.

\section{Author contributions}

A.G. conceived the study and compiled the data, M.L. performed statistical analysis and contributed to each draft, O.N. wrote the first draft of the paper, and revised each draft, and A.T. was involved in the collection and compilation of the data and reviewed the manuscript.

\section{Funding}

The study was not funded. Publication fee met by M.L.'s research account.

\section{Declaration of interest}

2 Large M, Smith G, Nielssen 0 . The relationship between the rate of homicide by those with schizophrenia and the overall homicide rate: a systematic review and meta-analysis. Schizophr Res 2009; 112: 123-9.

3 Tanay E. Homicidal behavior in schizophrenics. J Forens Sci 1987; 32: 1382-8.

4 coid J. The epidemiology of abnormal homicide and murder followed by suicide. Psychol Med 1983; 13: 855-60.

5 Taylor PJ, Gunn J. Homicides by people with mental illness: myth and reality. $\mathrm{Br}$ J Psychiatry 1999; 174: 9-14.

6 Large M, Smith G, Swinson N, et al. Homicide due to mental disorder in England and Wales over 50 years. Br J Psychiatry 2008; 193: 130-3.

7 Simpson Al, McKenna B, Moskowitz A, et al. Homicide and mental illness in New Zealand, 1970-2000. Br J Psychiatry 2004; 185: 394-8.

8 Gottlieb P, Gabrielsen G, Kramp P. Psychotic homicide in Copenhagen from 1959 to 1983. Acta Psychiatrica Scand 1987; 76: 285-92.

9 Gudjonsson GH, Petursson $\mathrm{H}$. Changing characteristics of homicide in Iceland Med Sci LaW 1986; 26: 299-303.

10 Penney SR, Prosser A, Grimbos T, et al. Time trends in homicide and mental illness in Ontario from 1987 to 2012: examining the effects of mental health service provision. Can J Psychiatry 2018; 63: 387-94.

11 Swinson N, Flynn SM, While D, et al. Trends in rates of mental illness in homicide perpetrators. Br J Psychiatry 2011; 198: 485-9.

12 Flynn S, Ibrahim S, Kapur N, et al. Mental disorder in people convicted of homicide: long-term national trends in rates and court outcome. Br J Psychiatry 2020; 218: 210-6.

13 Golenkov A, Tsymbalova A, Large $\mathrm{M}$, Nielssen O. An international perspective on homicide and schizophrenia: a study from Chuvashia. Schizophr Res 2011; 131: 258-9.

14 Golenkov A, Large M, Nielssen O, Tsymbalova A. Characteristics of homicide offenders with schizophrenia from the Russian Federation. Schizophr Res 2011; 133: 232-7.

15 Golenkov A, Large M, Nielssen O, Tsymbalova A. Homicide and mental disorder in a region with a high homicide rate. Asian J Psychiatr 2016; 23: 87-92.

16 Bukhanovsky AO, Gleyzer G. Forensic psychiatry in the Russian criminal justice system. Am Assoc Psychiatry Law 2001; 26: 16.

17 World Health Organization. The ICD-10 Classification of Mental and Behavioural Disorders. WHO, 1993 (https://www.who.int/classifications/icd/en/GRNBOOK. pdf).

18 Large M, Smith G, Nielssen O. Correspondence: the epidemiology of abnormal homicide and murder followed by suicide. Psychol Med 2009; 39: 699.

19 Segal SP. Civil commitment law, mental health services and US homicide rates. Soc Psychiatry Psychiatr Epidemiol 2012; 47: 1449-58.

20 Matveev M. Analysis of Russian Regions by Consumption of Alcohol. Realnoe vremya, 2018 (https://realnoevremya.ru/articles/124557-reyting-regionov-popotrebleniyu-alkogolya-v-2018-godu).

21 Neufeld M, Bunova A, Gornyi B, et al. Russia's national concept to reduce alcohol abuse and alcohol-dependence in the population 2010-2020: which policy targets have been achieved? Int J Envir Res Pub Health 2020; 17: 8270.

\section{References}

1 Fazel S, Gulati G, Linsell L, et al. Schizophrenia and violence: systematic review and meta-analysis. PLoS Med 2009; 6: e1000120. 